\title{
Effects of a novel curcumin derivative on the functions of kidney in streptozotocin-induced type 2 diabetic rats
}

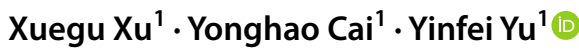

Received: 23 October 2017 / Accepted: 1 February 2018 / Published online: 26 March 2018

(c) The Author(s) 2018

\begin{abstract}
Objective B6, an analog of curcumin, is a compound isolated from a traditional Chinese medicine Turmeric. In this paper, we aimed to explore the efficacy of B6 on diabetic nephropathy and the related mechanisms.

Materials and methods The effects of B6 were studied on fast-blood glucose, serum creatinine, urea nitrogen, urine albumen/24 h, pathological changes of main organs, the levels of ACE2 and ACE2 mRNA in the rat model of diabetes induced by streptozotocin.

Results The results showed that B6 treatment could reduce serum creatinine, urea nitrogen, urine albumen/24 h, decrease the level of AngII, improve the renal pathological changes in diabetic rats and increase the levels of ACE2 and ACE2 mRNA. Conclusion These results suggested B6 could protect the renal function of diabetic rats. This study provided scientific basis for the further researches and clinical applications of B6.
\end{abstract}

Keywords Diabetic nephropathy $\cdot$ Curcumin derivative $\cdot$ B6 $\cdot$ Hyperglycemia

\section{Introduction}

Diabetic nephropathy (DN) is a common complication due to diabetes and the most common cause of end-stage renal disease (Kanwar et al. 2011). It has a strong impact on patients' qualities of life and survival rate. Therefore, studies of the treatment of DN have representative and guiding meanings.

Curcumin (1, 7-bis-(4-hydroxy-3-methoxyphenyl)-1, 6-heptadiene-3, 5-dione) is the main active component of the natural turmeric (Bengmark 2006). It has been extensively demonstrated as a multifunctional agent on cancer, inflammation, cholesterol-lowering and inflammatoryrelated diseases (Di et al. 2010; Shu et al. 2007; Sun et al. 2014). It showed that curcumin could significantly improve the renal functions of streptozotocin-induced diabetic rats. But the exact mechanisms remained to be further explained (Tikoo et al. 2008). However, the clinical applications of curcumin have been significantly limited by its low water solubility, short half-life in plasma and poor bioavailability

Yinfei Yu

$12734651 @ q q . c o m$

1 Department of Pharmacy, The Eye Hospital of Wenzhou Medical University, Wenzhou 325003, Zhejiang, China
(Pan et al. 2012; Epstein et al. 2010). Modifying the chemical structure of curcumin is one approach to overcome the poor bioavailability or further enhance its effects. A novel curcumin analogue, (E, E)-1, 5-bis(2-bromophenyl)1,4-pentadiene-3-one (B6), was identified as a high-active curcumin analogue screening from a series of new synthetic curcumin derivatives in vitro. The activities of curcumin and synthetic derivatives in vitro were mainly detected through

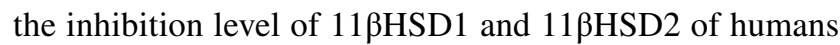
and rats. The results showed that B6 can strongly inhibit $11 \beta \mathrm{HSD} 1$ and $11 \beta \mathrm{HSD} 2$ in humans and rats. We set up B6 HPLC determination method in rat plasma and studied its pharmacokinetics in rats. The results showed the bioavailability of gastrointestinal tract in rats was $8.884 \pm 0.879 \%$ and the plasma half-life was $143.535 \pm 48.375$ min (Jiang et al. 2016).

In this study, we showed that B6 could reduce the levels of some biochemical indexes, improve the renal pathological changes, enhance the level of ACE2 and prevent renal injury in experimental diabetic rats. 


\section{Materials and methods}

\section{Drugs and chemicals}

Compound B6 was synthesized and characterized by Wenzhou Medical University. A high-performance liquid chromatography method was used to determine its purity $(98.67 \%)$. The structure of B6 is shown in Fig. 1. B6 was dissolved in corn oil for in vivo experiments. Streptozotocin (STZ) was purchased from Sigma-Aldrich (St. Louis, MO, USA).

\section{Animal experiments}

Protocols for animal studies were approved by the Wenzhou Medical University Animal Policy and Welfare Committee (Approved documents: 2009/APWC/0031). Fifity-eight male Wistar rats (160-180 g) were obtained from the Animal Center of Wenzhou Medical University (Wenzhou, China). Animals were housed at $21-25{ }^{\circ} \mathrm{C}$ with a $12: 12 \mathrm{~h}$ light/ dark cycle. Water and a standard diet were consumed. After 1 week, 58 Wistar rats were divided into two groups randomly: (1) the normal control group (NC Group, 10 Wistar rats); (2) high-fat- and high-sugar group (Model Group, 48 Wistar rats). The composition of high-sugar- and high-fat diet for Wistar rats was as follows: $68 \%$ common diet, $20 \%$ sucrose, $10 \%$ lard oil and $2 \%$ cholesterol. The obesity rat model can be built by feeding high-sugar- and high-fat diet for 4 weeks. After 4 weeks, the $48 \mathrm{Wistar}$ rats were treated with intraperitoneal injection of STZ $(30 \mathrm{mg} / \mathrm{kg}$ dissolved in citrate buffer, $\mathrm{pH}=4.5)$ to induce type 2 diabetes. The control group (10 Wistar rats) was intraperitoneally treated with the same volume of citrate buffer. The fasting-blood glucose was monitored using a glucometer (ACCU produced by Roche) on days 3 and 7 after STZ injection. The fasting-blood glucose $>8 \mathrm{mmol} / \mathrm{l}$ and random-blood glucose $>16.7 \mathrm{mmol} / \mathrm{l}$ were considered diabetic, then the 48 rats were randomly divided into four groups: (1) DM group $(n=12)$, (2) B6 low-dose group [B6(L), $n=12]$, (3) B6 middle-dose group [B6(M), $n=12]$, (4) B6 high-dose group $[\mathrm{B} 6(\mathrm{H}), n=12]$. The dosages of B6 were 1,3 and $9 \mathrm{mg} / \mathrm{kg}$ days, respectively. NC group and DM group were gastrointestinally administrated the same volume of corn oil. After 8 weeks, animals were sacrificed under $10 \%$ chloral hydrate anesthesia. Venous blood was taken after anesthesia. Kidney tissues were embedded in $4 \%$ paraformaldehyde for pathological analysis or were frozen in liquid nitrogen for gene and protein expression analysis.

\section{Determination of fast-blood glucose, serum creatinine, serum urea nitrogen and urine protein/24 h}

The levels of fasting-blood glucose, creatinine and urea nitrogen were determined by 7600-120ISE biochemical analyzer (Hitachi Limited, Tokyo, Japan) and the level of urine protein was determined by Coomassie brilliant blue staining according to the manufacturer's instructions.

\section{Determination of serum Angll and serum insulin}

The levels of serum AngII and insulin were measured by radioimmunoassay. Radioimmunoassay kit of serum AngII and insulin were purchased from Beijing SINO-UK Institute of Biotechnology (Beijing, China) and Northern Beijing Institute of Biotechnology (Beijing, China), respectively. The testing steps referred to the instructions of kit.

\section{Histopathology}

Kidneys were soaked in $4 \%$ paraformaldehyde solution for pathological analysis, embedded in paraffin and sectioned at $5 \mu \mathrm{m}$. After dehydration, sections were stained with haematoxylin and eosin. To evaluate the histopathological damage, each image of sections was examined by a light microscope (Olympus, Tokyo, Japan).

\section{Immunohistochemical assay of ACE2}

Immunohistochemistry was performed on paraffin sections $(5 \mu \mathrm{m})$ using a microwave-based antigen retrieval technique. The slides were incubated overnight at $4{ }^{\circ} \mathrm{C}$ in a humidified chamber with NUCB 2 rabbit anti-rat polyclonal<smiles>COc1cc(/C=C/C(=O)CC(=O)/C=C/c2ccc(O)c(OC)c2)ccc1O</smiles>

Curcumin<smiles>O=C(/C=C/c1ccccc1Br)/C=C/c1ccccc1Br</smiles>

B6

Fig. 1 Chemical structures of curcumin and B6 
antibody (1:100) (from Santa Cruz Biotechnology, Inc., Dallas, TX, USA) antibodies. The next day, each slice was added with a drop of non-biotinylated goat anti-rabbit polyperoxidase. After incubating for $30 \mathrm{~min}$ at room temperature, immunostaining was visualized with $0.05 \%$ diaminobenzidine. Sections were examined using a light microscope (Olympus, Tokyo, Japan) and imaged with a high-resolution camera at a magnification of $\times 400$. The negative control was using PBS solution (pH 7.2-7.6) instead of NUCB2.

Each slice selected 5 fields of vision $(\times 400)$ randomly. Image-pro plus 5.0 was used to measure intergral optical density (IOD) of each slice. The greater of IOD value showed the higher level of the protein. The average value of 6 times of IOD was calculated as the IOD value of the slice.

\section{RT-PCR assay of ACE mRNA and ACE2 mRNA}

Total RNA was isolated from kidney tissues using TRIZOL (Invitrogen, Carlsbad, CA, USA). DNA Marker I was purchased from Tiangen Biochemical Technology co., LTD (Beijing, China). Reverse transcription PCR were performed with an RT-PCR Kit (TaKaRa, Dalian, China). RT-PCR was carried out using the Eppendorf Realplex 4 instrument (Eppendorf, Hamburg, Germany).

\section{Statistical analysis}

All the research data were processed by SPSS 19.0. The measurement data were expressed as the Mean \pm SD. ANOVA and GraphPad Pro (GraphPad, San Diego, CA,
USA) were used to analyse the statistical significance between sets of data. Differences were considered to be significant at $p<0.05$.

\section{Results}

\section{B6 administration increased diabetic rats' body weight, but did not affect the ratio of kidney/body weight}

After 8 weeks, there was a significant decline in mean body weight in DM group and B6 treatment groups. But there was a significant increase in B6(L) and B6(M) groups. However, there were no significant differences in kidney/body weight ratio in DM group and B6 treatment groups (Table 1).

\section{Administration of B6 improved the metabolic and histological abnormality}

Table 2 showed that B6 treatment did not affect the blood glucose profile of diabetic rats after 8 weeks. The urea nitrogen, serum creatinine and urine protein $/ 24 \mathrm{~h}$ increased significantly in DM relative to control. After treatment with B6 for 8 weeks, the urea nitrogen, serum creatinine and urine protein/24 h were significantly reduced, especially in B6(M) group.

There were no significant differences of serum insulin values in DM group and B6 treatment groups (Table 3), indicating B6 treatment did not affect the serum insulin. Serum
Table 1 Comparisons of body weight, kidney weight and kidney/body weight ratio in different groups after 8 weeks $(\bar{x} \pm s)$

\begin{tabular}{lllll}
\hline Groups & Number & Body weight $(\mathrm{g})$ & Kidney weight $(\mathrm{g})$ & $\begin{array}{l}1000 \times \text { kidney/ } \\
\text { body weight ratio }\end{array}$ \\
\hline $\mathrm{NC}$ & 10 & $350.00 \pm 13.22$ & $1.31 \pm 0.21$ & $3.75 \pm 0.46$ \\
$\mathrm{DM}$ & 12 & $228.33 \pm 20.21^{* *}$ & $1.27 \pm 0.23$ & $5.53 \pm 0.60^{* *}$ \\
$\mathrm{~B} 6(\mathrm{~L})$ & 12 & $253.33 \pm 15.71^{* * \# \#}$ & $1.23 \pm 0.15$ & $4.84 \pm 0.32^{* *}$ \\
B6(M) & 12 & $255.00 \pm 16.07^{* * \# \#}$ & $1.24 \pm 0.16$ & $4.84 \pm 0.40^{* *}$ \\
B6(H) & 12 & $239.30 \pm 10.58^{* *}$ & $1.23 \pm 0.13$ & $5.15 \pm 0.39^{* *}$ \\
\hline
\end{tabular}

Data were presented as means $\pm \mathrm{SD} .{ }^{*} p<0.05,{ }^{*} p<0.01$ vs. NC group; ${ }^{*} p<0.05,{ }^{\# \#} p<0.01$ vs. DM group

Table 2 Comparisons of glucose, serum creatinine, urea nitrogen and urine albumen/24 $\mathrm{h}$ in different groups $(\bar{x} \pm \mathrm{s})$

\begin{tabular}{lllcc}
\hline Group & Blood glucose $\mathrm{mmol} / \mathrm{L})$ & Serum creatinine $(\mu \mathrm{mol} / \mathrm{L})$ & Urea nitrogen $(\mathrm{mmol} / \mathrm{L})$ & Urine albumen $\mathrm{mg} / 24 \mathrm{~h})$ \\
\hline NC & $8.33 \pm 0.97$ & $26.50 \pm 2.74$ & $7.51 \pm 1.62$ & $4.16 \pm 1.13$ \\
DM & $25.75 \pm 3.60^{* *}$ & $53.50 \pm 4.23^{* *}$ & $18.14 \pm 2.33^{* *}$ & $16.55 \pm 3.16^{* *}$ \\
B6(L) & $23.19 \pm 6.37^{* *}$ & $36.70 \pm 2.26^{* * \# \#}$ & $15.72 \pm 2.55^{* * \#}$ & $12.97 \pm 2.99^{* * \# \#}$ \\
B6(M) & $28.37 \pm 3.37^{* *}$ & $32.50 \pm 3.41^{* * \# \#}$ & $14.18 \pm 1.38^{* * \# \#}$ & $13.13 \pm 1.26^{* * \#}$ \\
B6(H) & $26.89 \pm 3.94^{* *}$ & $44.20 \pm 3.68^{* * \# \#}$ & $17.78 \pm 0.89^{* *}$ & $13.22 \pm 1.28^{* * \#}$ \\
\hline
\end{tabular}

Data were presented as means \pm SD. ${ }^{*} p<0.05,{ }^{* *} p<0.01$ vs. NC group; ${ }^{\#} p<0.05,{ }^{\# \#} p<0.01$ vs. DM group 
Table 3 Comparisons of insulin and AngII in different groups $(\bar{x} \pm s)$

\begin{tabular}{llll}
\hline Group & Number & Insulin $(\mathrm{mU} / \mathrm{L})$ & AngII $(\mathrm{pg} / \mathrm{ml})$ \\
\hline NC & 10 & $25.46 \pm 2.78$ & $436.90 \pm 51.01$ \\
DM & 12 & $37.02 \pm 4.36^{* *}$ & $868.28 \pm 73.15^{* *}$ \\
B6(L) & 12 & $39.21 \pm 4.00^{* *}$ & $633.86 \pm 46.49 * * \#$ \\
B6(M) & 12 & $37.55 \pm 2.83^{* *}$ & $555.26 \pm 46.04 * \#$ \\
B6(H) & 12 & $36.41 \pm 1.75^{* *}$ & $835.29 \pm 98.05^{* *}$ \\
\hline
\end{tabular}

Data were presented as means $\pm \mathrm{SD}$. $* \mathrm{P}<0.05, * * p<0.01$ vs. NC group; ${ }^{\#} p<0.05,{ }^{\# \#} p<0.01$ vs. DM group

AngII increased significantly in DM group relative to control. But there was a significant decrease in serum AngII in B6(L) and B6(M) groups (Table 3).

The H\&E staining (Fig. 2) revealed the glomerular hypertrophy, glomerulus with glomerulosclerosis and expansion, predominance of dense hyaline matrix and peripheral capillaries of thick stiff wall in the diabetic rats, whereas B6 treatment markedly ameliorated these diabetes-induced histopathological alterations. PAS further validated the histological renal improvements in B6 treatment groups when compared to that of untreated group. PAS staining (Fig. 3) demonstrated that B6 had a dose-dependent inhibition of diabetes-induced glycogen collection (purple plaques) in rats' kidney, especially in B6(M) group.

\section{B6 administration did not affect the levels of ACE MRNA in diabetic rats, but upregulated the levels of ACE2 mRNA and ACE2}

The balance between ACE and ACE2 is the key factor in regulating levels of angiotensin (Zhong et al. 2004; Song et al. 2013). Decreased expressions of ACE2 in kidney will
Fig. 2 Histomorphological changes of renal tissues in different groups $(\mathrm{HE}, \times 400)$ a NC group; b: DM group; c B6(L) group; d B6(M) group; e B6(H) group
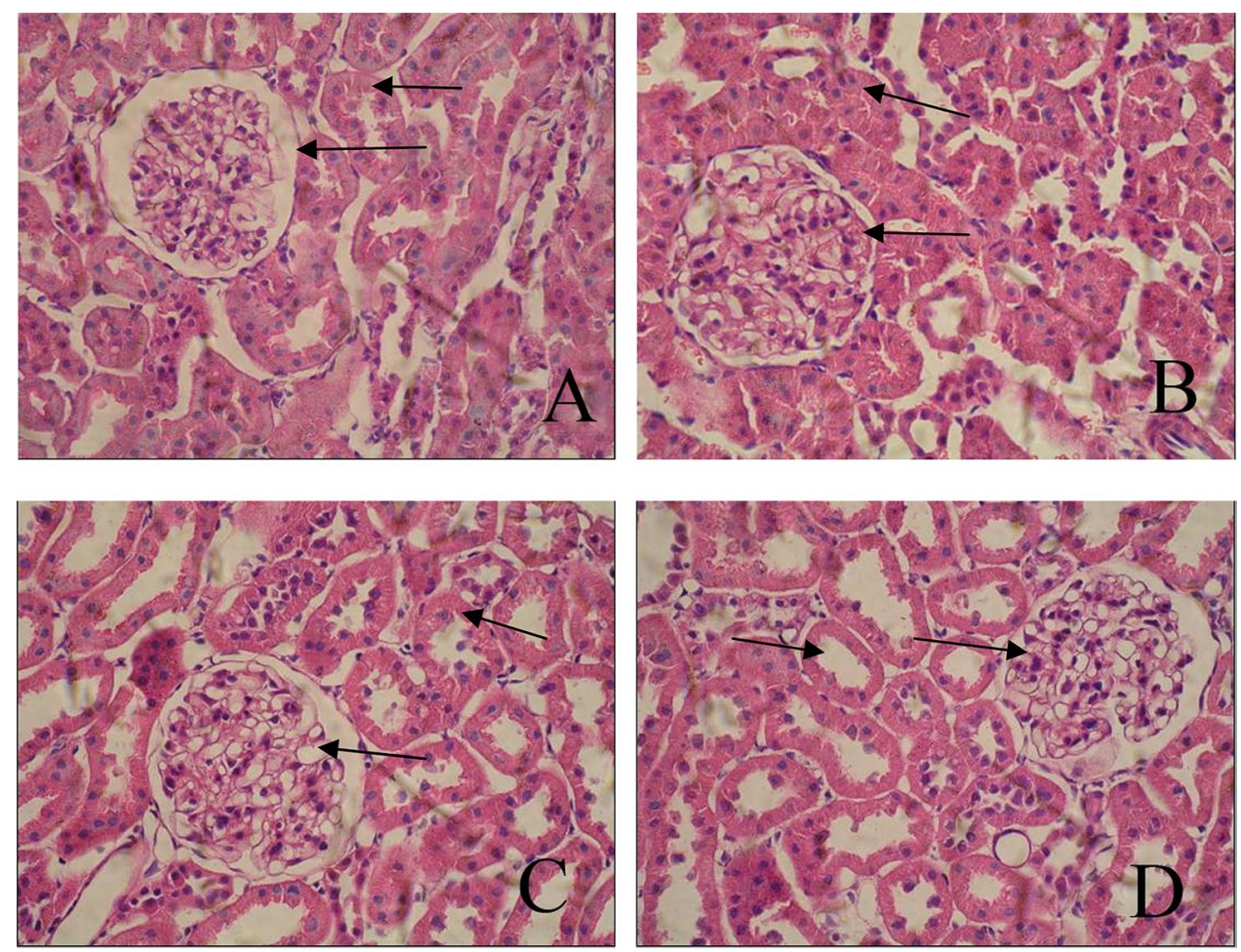

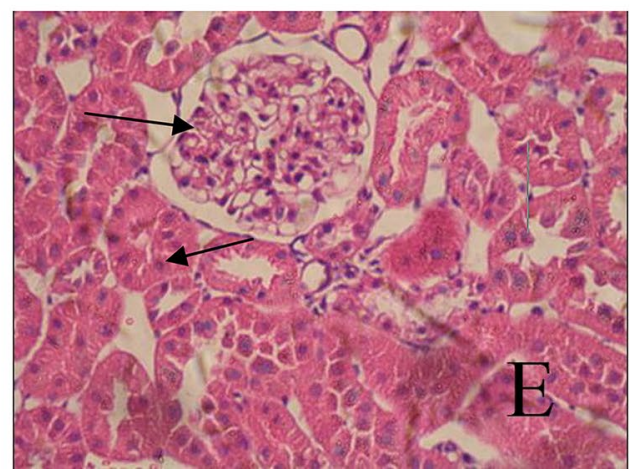


Fig. 3 Histomorphological changes of renal tissues in different groups (PAS, $\times 400$ ) a NC group; b: DM group; $\mathbf{c}$ : $\mathrm{B} 6(\mathrm{~L})$ group; d: B6(M) group; e: B6(H) group
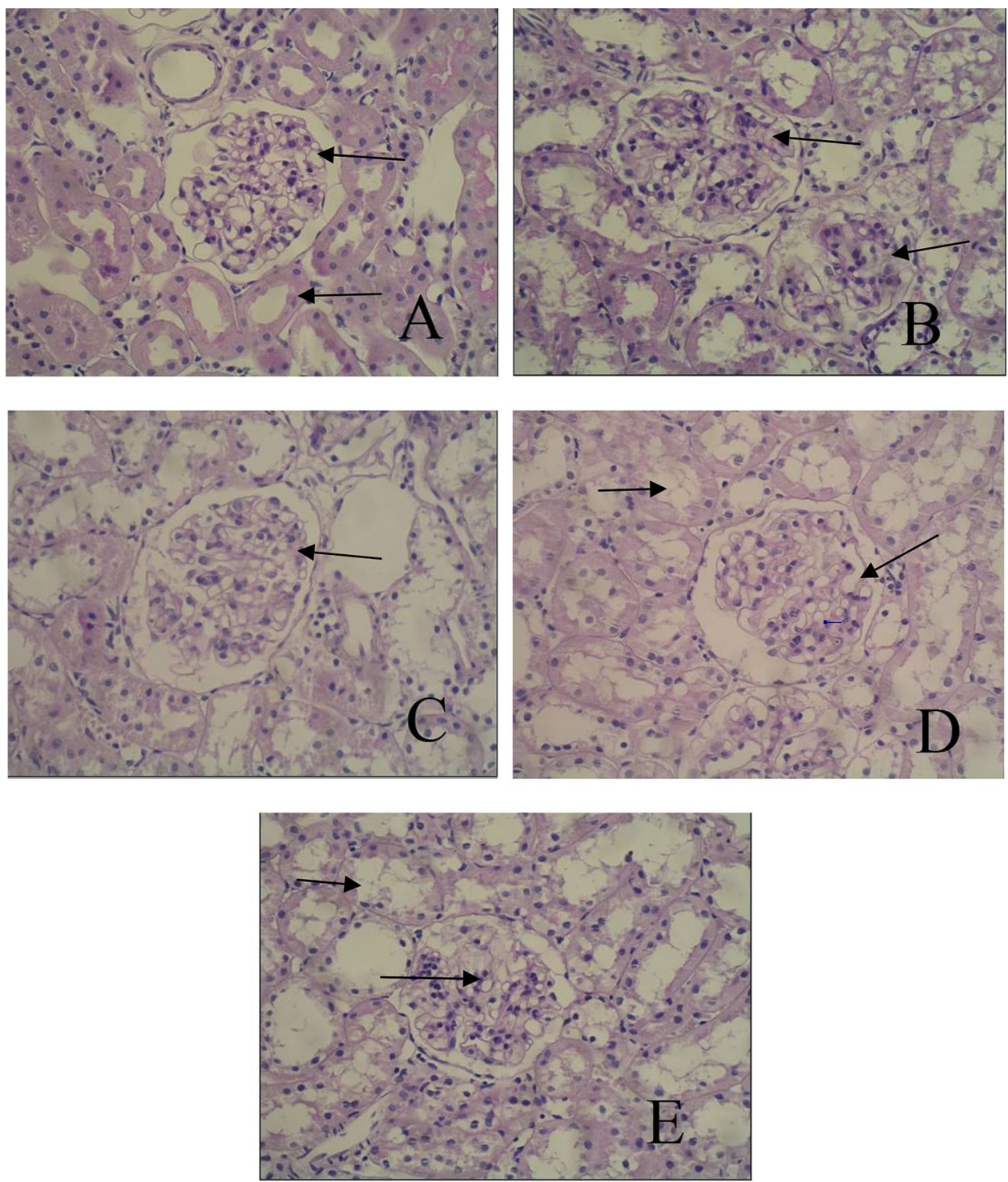

result in an increase of AngII in local renal tubule, which can cause the renal interstitial fibrosis (Bürgelová et al. 2005). Immunohistochemistry staining was performed to observe the levels of ACE2. The levels of ACE2 significantly decreased in DM group after 8 weeks, compared with control group. But there was a significant increase in B6(L) and B6(M) groups (Table 4, Fig. 4).

RT-PCR was used to determine the relative content of ACE mRNA and ACE2 mRNA to validate whether B6 treatment had effects on the levels of ACE mRNA and ACE2 mRNA. The results showed that B6 treatment did not affect the relative content of ACE mRNA (Table 5, Fig. 5). There was a significant reduction in ACE2 mRNA in DM group relative to control. The relative content of ACE2 mRNA increased remarkably in B6(L) and B6(M) groups. And after the treatment of B6, the level of ACE2 in B6(M) group was the same with that in control group (Table 5, Fig. 5).
Table 4 Comparisons of expression of ACE2 protein in different groups $(\bar{x} \pm \mathrm{s})$

\begin{tabular}{lll}
\hline Group & Number & Density (mean) \\
\hline NC & 5 & $0.388 \pm 0.027$ \\
DM & 6 & $0.238 \pm 0.021^{* *}$ \\
B6(L) & 6 & $0.333 \pm 0.022^{* * \#}$ \\
B6(M) & 6 & $0.364 \pm 0.036^{\# \#}$ \\
B6(H) & 6 & $0.251 \pm 0.021^{* *}$ \\
\hline
\end{tabular}

Data were presented as means $\pm \mathrm{SD}$. $* p<0.05, * * p<0.01$ vs. NC group; ${ }^{\#} p<0.05,{ }^{\# \#} p<0.01$ vs. DM group

\section{Acute toxicity test of B6}

Ten ICR mice were chosen randomly. Each mouse was intragastric administration at dose of B6 $3 \mathrm{~g} / \mathrm{kg}$. After 
Fig. 4 Expression of ACE2 in different groups(Immunohisto chemistry, $\times 400)$ a $\mathrm{NC}$ group; b DM group; c B6(L) group; $\mathbf{d}$ B6(M) group; e B6(H) group; f negative control group
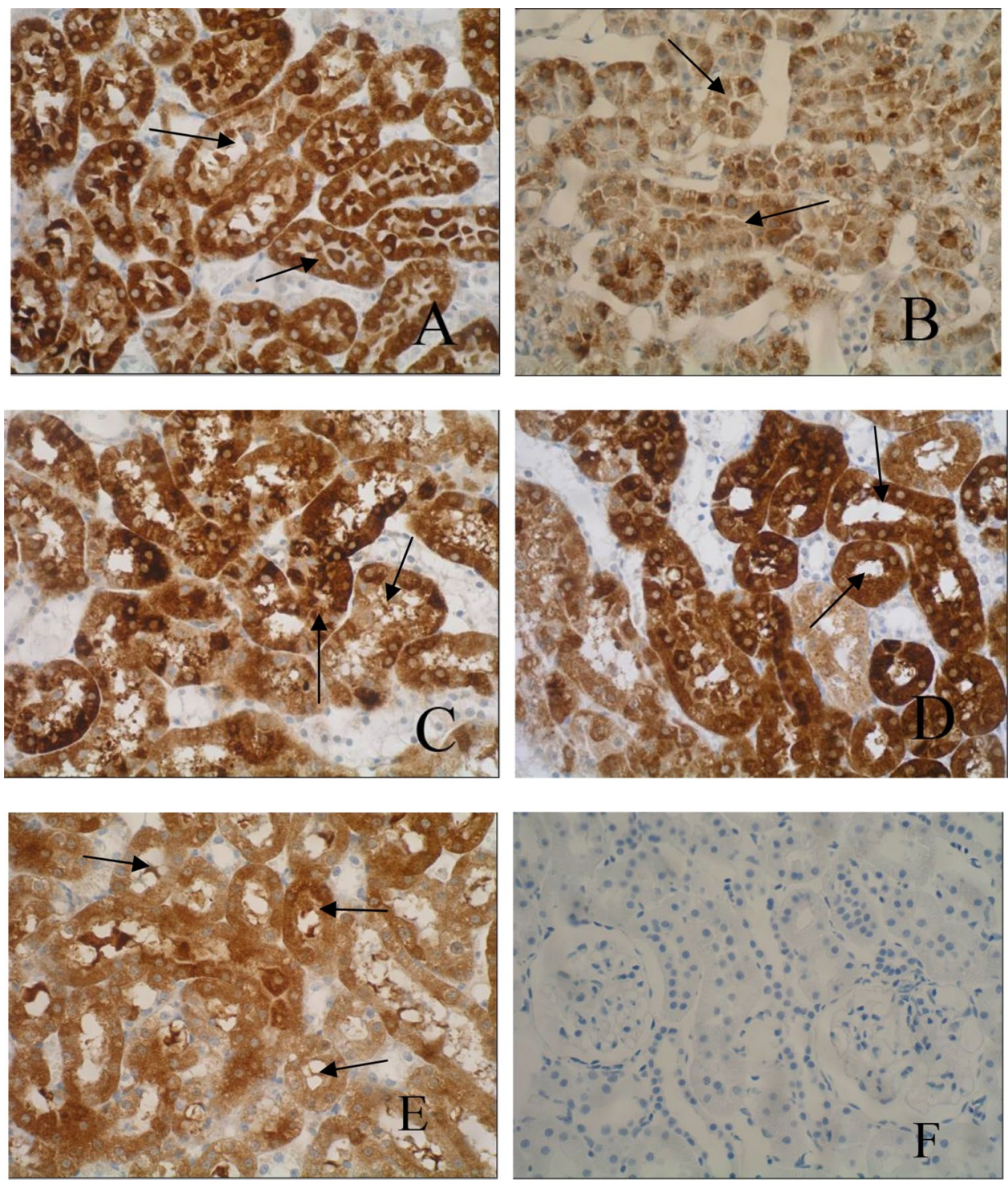

Table 5 Comparisons of relative content of ACE mRNA and ACE2 mRNA in different groups $(\bar{x} \pm \mathrm{s})$

\begin{tabular}{llll}
\hline Group & $\mathrm{N}$ & ACE/ $\beta$-actin mRNA & ACE2/ $\beta$-actin mRNA \\
\hline NC & 5 & $0.540 \pm 0.022$ & $0.577 \pm 0.040$ \\
DM & 6 & $0.437 \pm 0.039^{* *}$ & $0.387 \pm 0.032^{* *}$ \\
B6(L) & 6 & $0.422 \pm 0.053^{*}$ & $0.458 \pm 0.025^{* * \#}$ \\
B6(M) & 6 & $0.443 \pm 0.023^{* *}$ & $0.544 \pm 0.072^{\#}$ \\
B6(H) & 6 & $0.391 \pm 0.048^{* *}$ & $0.319 \pm 0.051^{* *}$ \\
\hline
\end{tabular}

Data were presented as means $\pm \mathrm{SD}$. $* p<0.05, * * p<0.01$ vs. NC group; ${ }^{\#} p<0.05,{ }^{\# \#} p<0.01$ vs. DM group

administration, ten ICR mice were given natural drink and diet. During 3 days of observation, no mouse died and all observation measures were normal. Acute toxicity test of mice showed B6 was safe.

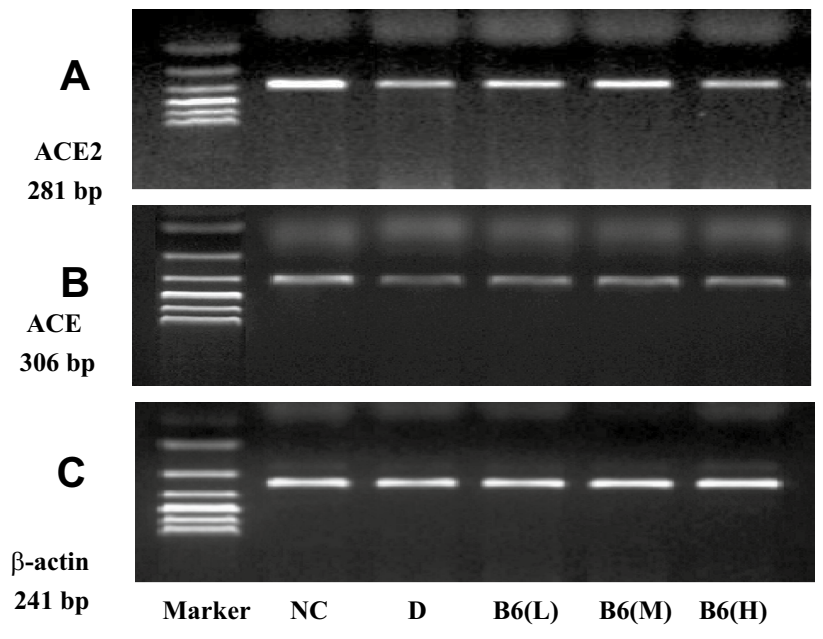

Fig. 5 Levels of ACE2 mRNA, ACE mRNA and $\beta$-actin mRNA in different groups 


\section{Discussion}

The treatments of DN usually focus on insulin, angiotensin-converting enzyme inhibitors and angiotensin receptor antagonist. In this study, we demonstrated that a novel curcumin analogue, B6, efficiently attenuated diabetic renal injury via reductions of the serum creatinine, urea nitrogen and urine protein $/ 24 \mathrm{~h}$. Improvements of renal function in B6-treated groups can also be seen in histopathological changes.

Renin-angiotensin system (RAS) is a major contributor to systemic blood pressure. Recently, it has also been found as playing an important role in the development of DN (Carey and Siragy 2003). AngII is the main molecule of RAS, and relative with all pathological changes of DN, such as renal hemodynamic changes, accumulation of extracellular matrix, productions of the cytokines, podocyte injury, proteinuria and interstitial nephritis (Wolf 2004). Reduction of AngII can significantly improve the development of glomerular sclerosis and proteinuria (Ahmad et al. 1997). Our results showed AngII had a significant decrease in B6 treatment groups.

Angiotensinogen is broken down by renin to give angiotensin I (AngI), and angiotensin-converting enzyme (ACE) subsequently converts AngI to angiotensin II (AngII). In the kidneys, the ACE-AngII type 1 (AT1) axis (the classical RAS) promotes sodium and water retention, oxidative stress, vasoconstriction, cell proliferation, inflammation, and fibrosis. In 2000, ACE2 (Tipnis et al. 2000; Donoghue et al. 2000) was discovered, which indicated that the RAS is more complex than was previously imagined. ACE2 counteracts the effects of ACE by catabolizing AngII to produce Ang 1-7. The balance between the effects of these two molecules affects the renal RAS, and hence, the ACE/ ACE2 ratio might represent the key parameter that is driving the regulation of the renal RAS (Bernardi et al. 2012; Ye et al. 2004; Wakahara et al. 2007; Soler et al. 2009; Batlle et al. 2012; Soler et al. 2013).

Therefore, ACE2 plays an important role in the development of renal diseases, such as diabetic nephropathy. It is suggested that the main priority of the RAS is to achieve an appropriate balance between ACE and ACE2 activity. The ACE-AngII-AT1 axis has been suggested to have detrimental effects on the RAS, whereas the ACE2Ang 1-7-Mas axis counteracts the ACE-AngII-AT1 axis and seems to play a renoprotective role (Iwai and Horiuchi 2009). In a study involving diabetic rats, Tikellis et al. (2003) observed reduced renal expression levels of ACE and ACE2 mRNA, higher glomerular ACE and ACE2 protein expression levels, and lower tubular ACE and ACE2 protein expression levels at 24 weeks after the administration of STZ. In a study examining $\mathrm{db} / \mathrm{db}$ mice without nephropathy, Ye et al. (2004) detected higher ACE2 protein expression and lower ACE protein expression in the animal's renal tubules, which resulted in renoprotective effects. Moreover, they speculated that reduced ACE2 expression and upregulated ACE expression gradually induce kidney damage in diabetes (Ye et al. 2004).

Taken together, studies had suggested that upregulated ACE expression and downregulated ACE2 expression were seen at both the glomerular and tubular levels in established diabetic nephropathy.

The studies showed that there was a significant decrease of ACE in DM group and B6-treated groups relative to control, which may be related to the consumption of a large amount of ACE in the process of conversion from AngI to AngII. B6 did not affect on the activities of ACE in diabetic nephropathy rats, but could upregulate ACE2 and ACE2 mRNA, which regulated the balance of circulation and local blood vessels, maintained renal blood flow and reached the purpose of anti-renal fibrosis finally.

\section{Conclusion}

Generally, the studies showed that B6 had positive effects on diabetic nephropathy. These results indicated that B6 was a new type of curcumin derivatives with great potential for development. We had also filtered other new curcumin derivatives, and only a few curcumin derivatives showed good characteristics. The absorption and metabolism of B6 was better than curcumin. And our laboratory study showed that B6 had an important role in regulating blood lipid and protecting fatty liver. Besides, no obvious acute toxic effects were observed. This study provided scientific basis for the further researches and clinical applications of B6.

Acknowledgements I acknowledge that this research work is carried out without any financial assistance from the university.

\section{Compliance with ethical standards}

Conflict of interest The authors have no conflicts of interest to disclose.

Open Access This article is distributed under the terms of the Creative Commons Attribution 4.0 International License (http://creativecommons.org/licenses/by/4.0/), which permits unrestricted use, distribution, and reproduction in any medium, provided you give appropriate credit to the original author(s) and the source, provide a link to the Creative Commons license, and indicate if changes were made. 


\section{References}

Ahmad J, Siddiqui MA, Ahmad H (1997) Effective postponement of diabetic nephropathy with enalapril in normotensive type 2 diabetic patients with microalbuminuria. Diabetes Care 20:1576-1581

Batlle D, Wysocki J, Soler MJ, Ranganath K (2012) Angiotensin-converting enzyme 2 : enhancing the degradation of angiotensin ii as a potential therapy for diabetic nephropathy. Kidney Int 81:520-528

Bengmark S (2006) Curcumin, an atoxic antioxidant and natural nfkappab, cyclooxygenase-2, lipooxygenase, and inducible nitric oxide synthase inhibitor: a shield against acute and chronic diseases. J Parenter Enter Nutr 30:45-51

Bernardi S, Toffoli B, Zennaro C, Tikellis C, Monticone S, Losurdo P, Bellini G, Thomas MC, Fallo F, Veglio F, Johnston CI, Fabris B (2012) High-salt diet increases glomerular ace/ace 2 ratio leading to oxidative stress and kidney damage. Nephrol Dialysis Transpl 27:1793-1800

Bürgelová M, Kramer HJ, Teplan V, Thumová M, Ccaronervenka L (2005) Effects of angiotensin-(1I[ndash]17) blockade on renal function in rats with enhanced intrarenal ang ii activity. Kidney Int 67:1453-1461

Carey RM, Siragy HM (2003) The intrarenal reninangiotensin system and diabetic nephropathy. Trends Endocrinol Metab 14:274-281

Di JB, Gu ZL, Zhao XD, Qian PG, Jiang XG, Guo CY (2010) Advances in studies on antioxidant and anti-inflammation of curcumin. Chin Tradit Herbal Drugs 41:a18-a21

Donoghue M, Hsieh F, Baronas E, Godbout K, Gosselin M, Stagliano N, Donovan M, Woolf B, Robison K, Jeyaseelan R, Breitbart RE, Acton S (2000) A novel angiotensin-converting enzyme-related carboxypeptidase (ace2) converts angiotensin I to angiotensin 1-9. Circ Res 87:E1-E9

Epstein J, Sanderson IR, Macdonald TT (2010) Curcumin as a therapeutic agent: the evidence from in vitro, animal and human studies. Br J Nutr 103:1545-1557

Iwai M, Horiuchi M (2009) Devil and angel in the renin-angiotensin system: ace-angiotensin II-at1 receptor axis vs. ace2-angiotensin-(1-7)-mas receptor axis. Hypertens Res 32:533-536

Jiang HY, Xu XG, Wang YL, Wu B (2016) Determination of curcumin derivative $\mathrm{B} 6$ in rat plasma by HPLC and its application to pharmacokinetics. Lat Am J Pharm 35:749-755

Kanwar YS, Sun L, Xie P, Liu F, Chen S (2011) A glimpse of various pathogenetic mechanisms of diabetic nephropathy. Ann Rev Pathol 6:395-423

Pan Y, Wang Y, Cai L, Cai Y, Hu J, Yu C, Li J, Feng Z, Yang S, Li $X$, Liang $G$ (2012) Inhibition of high glucose-induced inflammatory response and macrophage infiltration by a novel curcumin derivative prevents renal injury in diabetic rats. $\mathrm{Br} \mathrm{J}$ Pharmacol 166:1169-1182
Shu JC, Hai-En WU, Xin-Jun PI, Ya-Jun HE, Xia L, Fang L (2007) Curcumin inhibits lipid peroxidation and the expression of TGF$\beta 1$ and PDGF in the livers of rats with hepatic fibrosis. Chin J Pathophysiol 23:2405-2409

Soler MJ, Ye M, Wysocki J, William J, Lloveras J, Batlle D (2009) Localization of ace 2 in the renal vasculature: amplification by angiotensin ii type 1 receptor blockade using telmisartan. Am J Physiol 296:F398-F405

Soler MJ, Wysocki J, Batlle D (2013) ACE2 alterations in kidney disease. Nephrol Dial Transplant 28:2687-2697

Song B, Zhang ZZ, Zhong JC, Yu XY, Oudit GY, Jin HY, Lu L, Xu YL, Kassiri Z, Shen WF, Gao PJ, Zhu DL (2013) Loss of angiotensinconverting enzyme 2 exacerbates myocardial injury via activation of the CTGF-fractalkine signaling pathway. Circ J 77:2997-3006

Sun LN, Yang ZY, Lv SS, Liu XC, Guan GJ, Liu G (2014) Curcumin prevents diabetic nephropathy against inflammatory response via reversing caveolin-1 tyr14 phosphorylation influenced tlr4 activation. Int Immunopharmacol 23:236-246

Tikellis C, Johnston CI, Forbes JM, Burns WC, Burrell LM, Risvanis J, Cooper ME (2003) Characterization of renal angiotensin-converting enzyme 2 in diabetic nephropathy. Hypertension 41:392-397

Tikoo K, Meena RL, Kabra DG, Gaikwad AB (2008) Change in post-translational modifications of histone h3, heat-shock protein-27 and map kinase p38 expression by curcumin in streptozotocin-induced type i diabetic nephropathy. Br J Pharmacol 153:1225-1231

Tipnis SR, Hooper NM, Hyde R, Karran E, Christie G, Turner AJ (2000) A human homolog of angiotensin-converting enzyme. cloning and functional expression as a captopril-insensitive carboxypeptidase. J Biol Chem 275:33238-333243

Wakahara S, Konoshita T, Mizuno S, Motomura M, Aoyama C, Makino Y, Kato N, Koni I, Miyamori I (2007) Synergistic expression of angiotensin-converting enzyme (ace) and ace 2 in human renal tissue and confounding effects of hypertension on the ace to ace 2 ratio. Endocrinology 148:2453-2457

Wolf G (2004) New insights into the pathophysiology of diabetic nephropathy: from haemodynamics to molecular pathology. Eur J Clin Invest 34:785-796

Ye M, Wysocki J, Naaz P, Salabat MR, LaPointe MS, Batlle D (2004) Increased ace 2 and decreased ace protein in renal tubules from diabetic mice: a renoprotective combination? Hypertension 43:1120-1125

Zhong JC, Huang DY, Yang YM, Li YF, Liu GF, Song XH, Du K (2004) Upregulation of angiotensin-converting enzyme 2 by alltrans retinoic acid in spontaneously hypertensive rats. Hypertension 44:907-912 